\title{
Budesonide as a first line therapy in autoimmune hepatitis: A systematic review
}

Ibrahim Mahmoud Ajwah ${ }^{1}$, Mohammed Abdullah Albalawi ${ }^{1}$, Bashayer Jazza Alenazi ${ }^{1}$, Saif

Mohammed Alamri ${ }^{1}$, Faris Essa Qubays ${ }^{1}$, Abdullah Mahmoud Ajwah ${ }^{1}$, Abdullah Saeed Alghamdi ${ }^{1}$,

Nader Awad Alanazi ${ }^{1}$, Abdul wahab Ali Asseri ${ }^{1}$, Kholoud Abdullah Algamdi ${ }^{1}$, Solaiman Hosaian

Alenezi ${ }^{1}$, Ahmad Jamil Makai ${ }^{1}$, Mohamed Omar Amer ${ }^{2}$

1. Internal Medicine Resident, King Salman Armed Forced Hospital, Tabuk, Saudi Arabia

2. Head of Gastroenterology Department, Gastroenterology and Hepatology Consultant, King Salman Armed

Forced Hospital, Tabuk, Saudi Arabia

\section{RESEARCH}

Please cite this paper as: Ajwah I, Albalawi M, Alenazi B, Alamri S, Qubays F, Ajwah A, Alghamdi A, Alanazi N, Asseri A, Algamdi K, Alenezi S, Makai A, Amer M. Budesonide as a first line therapy in autoimmune hepatitis: A systematic review. AMJ 2020;13(6):207-212.

https://doi.org/10.35841/1836-1935.13.6.207-212

Corresponding Author:

Ibrahim Mahmoud Ajwah

King Salman Armed Forced Hospital PO Box 3458 Tabuk

51937, Saudi Arabia.

Email: aj.wa@hotmail.com

\section{ABSTRACT}

\section{Background}

Autoimmune hepatitis (AIH) Is a chronic liver disease with female predominance. Treatment of this condition required usually a long-term corticosteroid therapy.

\section{Aims}

Current review aimed to summarize the efficacy of budesonide as a first line treatment in $\mathrm{AlH}$.

\section{Methods}

Pub Med, Google Scholar, and EBSCO databases were systematically search for relevant articles . The terms autoimmune hepatitis , budesonide, prednisolone and azathioprine were used. Out of hundred and six, only five fulfilled the inclusion criteria.

\section{Results}

Out of 106 articles, only 5 included in this review. All patients included in current review were steroid naive.
Budesonide in dose of $3 \mathrm{mg}$ trice a day was the used in 2 out of 5 studies both document complete platelet response in 50-80 per cent. Azathioprine was added to budesonide in 3 out of 5 studies, 60 per cent of the budesonide treated patient had a complete platelet response versus $30-40$ per cent of prednisolone treated group.

\section{Conclusion}

In non-cirrhotic AlH patients, budesonide was as effective as prednisolone with fewer steroid related side effects.

\section{Key Words}

Autoimmune hepatitis, budesonide, azathioprine

\section{What this study adds:}

\section{What is known about this subject?}

Prednisolone monotherapy or combined with azathioprine is a standard treatment regimen for $\mathrm{AlH}$.

\section{What new information is offered in this study?}

Budesonide is a promising synthetic corticosteroid for treatment of AlH with low steroid related side effects.

3. What are the implications for research, policy, or practice?

Budesonide as well as other agent such as

cyclophosphamide, are investigatory medication. Patients with AlH should be treated with the standard medications.

\section{Background}

Autoimmune hepatitis (AIH) is a chronic liver disease characterized biochemically by elevation in serum aminotransferases (AST- ALT) and immunoglobulin G (IgG), serologically by the presence of autoantibodies such as antinuclear antibody , anti-smooth antibody , and anti -liver kidney microsomal antibody or anti -soluble liver antigen antibody and histologically by interface hepatitis. ${ }^{1}$ As a 
result of this chronic inflammatory process, cirrhosis and subsequently occurrence of hepatocellular carcinoma. ${ }^{2}$

Corticosteroid in the form of high dose prednisolone or a lower dose of prednisolone in combination with azathioprine is the standard treatment of $\mathrm{AlH}$ with remission rate reaching up to 80 per cent. Since majority of the patients will require a long-term maintenance therapy, they are at increased risk of steroid related side effect (1044 per cent). ${ }^{2}$

To avoid such a risk , budesonide, a synthetic steroid with high hepatic first pass effect and low steroid related side effects was used in clinical trials and compared with the standard treatment regarding it is efficacy and side effects profile. $^{3}$

The current review aimed to summarize the available studies that investigated budesonide as a first line treatment for AlH.

\section{Method}

A systematic electronic search was conducted including the Pub Med, Google Scholar, and EBSCO using the following terms in different combinations : autoimmune hepatitis, budesonide, prednisolone and azathioprine. We included all full texts randomized controlled trials and observational , studies investigated budesonide as a first line treatment for $\mathrm{AlH}$. Studies published in abstracts were not included. Hundred and six articles were identified , only five of them fulfilled the inclusion and exclusion criteria . The abstracts and full texts were screened independently by two authors (MB, Al). The authors extracted the data, and then the author's names, year and region of publication , the study type, period of study, and the result were reported. Table 1 The PRISMA Chart was used in the current survey (Figure 1).

\section{Results}

After exclusion of irrelevant and duplicated studies as well as review articles, five studies met the inclusion criteria. ${ }^{4-8}$ Included studies aimed to evaluate the use of budesonide as a first line treatment for $\mathrm{AlH}$. The total number of $\mathrm{AlH}$ patients included in this review were 290 , the sample size ranged from 7 in Wiegand et al. ${ }^{4}$ study to 207 in Manns et al. ${ }^{6}$ The studies duration range between 3-9 months.

Budesonide in dose of $3 \mathrm{mg}$ thrice a day as a monotherapy was assessed in two studies . Wiegand et al., ${ }^{4}$ included 12 patients with autoimmune hepatitis, complete remission was achieved in 7 out of 12 (58\%). Similarly, Csepregi and collage, ${ }^{5}$ conducted a pilot study where $83 \%$ of the patients accomplished complete clinical and biochemical remission. Combining budesonide with azathioprine was also investigated in autoimmune hepatitis. Manns et al., conducted a randomized trial included 207 autoimmune hepatitis patients who were assigned to receive either budesonide at dose of $3 \mathrm{mg}$ two or three times daily or prednisone at $40 \mathrm{mg}$ daily. Both regiments were combined with azathioprine ( 1 to $2 \mathrm{mg} / \mathrm{kg}$ daily). Complete biochemical remission was significantly higher among budesonide treated patients compared with those who received prednisolone (47 and 18 percent, respectively). In addition, fewer glucocorticoid-related side effects were observed in budesonide group. The efficacy of budesonide and azathioprine combination was also shown in the study by Efe et al. ${ }^{7}$ In this study authors concluded that budesonide is an effective treatment option for the management of $\mathrm{AlH}$, with a low incidence of side effects in patients without findings of advanced liver disease.

Concerning paediatric patients , oral budesonide with azathioprine can induce and maintain remission in paediatric patients with autoimmune hepatitis and may be considered an alternative therapy to prednisone, this result has been reported by Woynarowski 8 who compared oral budesonide with oral prednisone in combination with azathioprine In autoimmune hepatitis patients aged 9-17 years and observed a comparable percentage of remission among the two study arms.

\section{Discussion}

Once indicated, treatment of autoimmune hepatitis should be initiated. Two established treatment regimens for severe autoimmune hepatitis (AIH) are equally effective and include high dose of prednisone (60mg daily) or a lower dose (30mg daily) co-administered with azathioprine (50mg or $1-2 \mathrm{mg} / \mathrm{kg}$ body weight ). Both regiments are recommended in clinical guidelines. For instance, the American Association for the Study of Liver Diseases

(AASLD) recommend both treatment options, with the latter being preferred. ${ }^{9}$

Although the combination regiment is the preferred one, treatment should be individualized . As an illustration, prednisone as a sole medication is a reasonable choice in individuals with cytopenia, pregnancy and active malignancies. ${ }^{10-12}$

Corticosteroid-related side effects are the most common causes for premature drug withdrawal in autoimmune hepatitis. It is ranging from cosmetic side effect such as 
weight gain, acne and alopecia to as severe as osteopenia with vertebral compression, diabetes, psychosis and pancreatitis. $^{13,14}$

To avoid such a serious side effects. Budesonide, a synthetic steroid with a high hepatic first pass metabolism and less steroid related side effects , were evaluated in five randomized control trials as an alternative to prednisone in the treatment of $\mathrm{AlH}$. $^{4-8}$

Finally, with the exception of Manns et al. ${ }^{6}$ study, all included trials have very small sample size. The efficacy of budesonide was ranged from $16 \%$ in Woynarowski et al. ${ }^{8}$ study to $83 \%$ in Csepregi et al. ${ }^{5}$ study, this variation in the efficacy could be explained by different treatment duration as well as definition of remission.

\section{Conclusion}

In absence of advance liver disease , budesonide is a promising treatment option especially for patients prone to develop steroid specific side effects such as osteoporosis in postmenopausal females. Current studies support usage of budesonide. More randomized trials are needed to validate this finding and provide a solid information about both efficacy as indicated biochemically and histologically as well as information about long term safety.

\section{References}

1. Vergani D, Mieli-Vergani G. Pharmacological management of autoimmune hepatitis. Expert Opin Pharmacother. 2011;12(4):607-13.

2. Krawitt EL. Autoimmune hepatitis. $N$ Engl JMed. 2006;354(1):54-66.

3. Danielsson A, Prytz H. Oral budesonide for treatment of autoimmune chronic active hepatitis. Aliment Pharmacol Ther. 1994;8:585-590.

4. Wiegand J, Schüler A, Kanzler S, et al. Budesonide in previously untreated autoimmune hepatitis. Liver Int. 2005;25(5):927-34.

5. Csepregi A, Röcken C, Treiber G, et al. Budesonide induces complete remission in autoimmune hepatitis. World J Gastroenterol. 2006;12(9):1362-69.

6. Manns MP, Woynarowski M, Kreisel $W$, et al. BUDinduces remission more effectively than prednisone in a controlled trial of patients with autoimmune hepatitis. Gastroenterology. 2010;139(4):1198-206.

7. Efe C, Ozaslan E, Kav T, et al. Liver fibrosis may reduce the efficacy of budesonide in the treatment of autoimmune hepatitis and overlap syndrome. Autoimmun Rev. 2012;11:330-334.

8. Woynarowski M, Nemeth A, Baruch Y, et al. Budesonide versus prednisone with azathioprine for the treatment of autoimmune hepatitis in children and adolescents. J Pediatr. 2013163(5):1347-53.

9. Manns MP, Czaja AJ, Gorham JD, et al. Diagnosis and management of autoimmune hepatitis. Hepatology. 2010;51:2193-2213. doi:10.1002/hep.23584

10. Ben Ari Z, Mehta A, Lennard L, et al. Azathioprineinduced myelosuppression due to thiopurine methyltransferase deficiency in a patient with autoimmune hepatitis. J Hepatol. 1995;23:351-354.

11. Rosenkrantz JG, Githens JH, Cox SM, et al. Azathioprine (Imuran) and pregnancy. Am J Obstet Gynecol. 1967;97:387-394.

12. Penn I. Tumor incidence in human allograft recipients. Transplant Proc. 1979;11:1047-1051.

13. Summerskill WHJ, Korman MG, Ammon HV, et al. Prednisone for chronic active liver disease: dose titration, standard dose and combination with azathioprine compound. Gut. 1975;16:876-883.

14. Czaja AJ. Safety issues in the management of autoimmune hepatitis. Expert Opin Drug Safety. 2008;7:319-333.

\section{PEER REVIEW}

Not commissioned. Externally peer reviewed.

\section{CONFLICTS OF INTEREST}

The authors declare that they have no competing interests.

\section{FUNDING}

None 
Table 1: The included studies outcomes regarding effectiveness of budesonide

\begin{tabular}{|c|c|c|c|}
\hline & Author-Year & Methods & Results \\
\hline 1 & Wiegand et $\mathrm{al}^{4}$ & $\begin{array}{c}\text { Study design: open, uncontrolled multicenter phase } \\
\text { IIA trial. } \\
\text { Study aim: To assessed the efficacy and safety of } \\
\text { BUD in AIH. } \\
\text { Inclusion criteria: Patients (age 10-70 years) with } \\
\text { the first diagnosis of AIH according to the scoring } \\
\text { system of the International Autoimmune Hepatitis } \\
\text { Group. } 2 \\
\text { Treatment regimen: } 3 \text { mg BUD thrice daily. } \\
\text { Follow-up duration: } 3 \text { months } \\
\text { Primary endpoint: induction of remission. } \\
\text { Definition of remission: Drop of AST and ALT } \geq \text { two } \\
\text { times } \\
\text { the upper limit of normal. }\end{array}$ & $\begin{array}{l}\text { Study completer; } 12 \text { participants ( } 4 \text { male, } 8 \text { female) } \\
\text { Result: } \\
\text { complete remission: } 7 \text { out of } 12(58 \%) \\
\text { Partial remission: } 3 \text { out of } 12(25 \%) \\
\text { Therapy was tolerated well in (83.3\%). } \\
\text { Limitation: Long term efficacy and safety con not be } \\
\text { concluded due to short follow up duration. } \\
\text { Conclusion: BUD monotherapy was effective in the } \\
\text { induction of remission and well tolerated in } \\
\text { treatment naïve patients with AIH. }\end{array}$ \\
\hline 2 & Csepregi et al ${ }^{5}$ & $\begin{array}{c}\text { Study design: Opine pilot study. } \\
\text { Study aim: To assessed the efficacy and safety of } \\
\text { BUD in AIH. } \\
\text { Inclusion criteria: AIH diagnosed based on the } \\
\text { International Autoimmune Hepatitis Group. } \\
\text { Treatment regimen: BUD 3mg thrice daily } \\
\text { Follow-up duration: At least } 24 \text { weeks. } \\
\text { Primary endpoint: induction of remission. } \\
\text { Definition of remission: Absence of clinical } \\
\text { symptoms, normal serum ALT, ALP, and IgG levels. }\end{array}$ & $\begin{array}{l}\text { Study completer: } 7 \text { Participants } \\
\text { Result: Fifteen (83\%) patients had a complete clinical } \\
\text { and biochemical remission. Ten patients, including } \\
\text { five with acute hepatitis, were given BUD as first-line } \\
\text { therapy, of which seven enter remission. } \\
\text { Limitation: Small sample size, short follow-up } \\
\text { duration. } \\
\text { Conclusion: BUD is effective in remission induction } \\
\text { in the majority of AIH patients. Side effects and } \\
\text { treatment failure was mainly observed in patients } \\
\text { with } \\
\text { liver cirrhosis. }\end{array}$ \\
\hline 3 & Manns et al 6 & $\begin{array}{l}\text { Study design: Prospective double-blind Randomized } \\
\text { active controlled trial. } \\
\text { Study aim: compared the effects of BUD and } \\
\text { prednisone, both in combination with azathioprine. } \\
\text { Inclusion criteria: Participants } 10-70 \text { years of age } \\
\text { with diagnosis of AIH according to the criteria of the } \\
\text { International Autoimmune Hepatitis Group. } \\
\text { Treatment regimen: AZA (1-2mg/kg/d).) plus } \\
\text { either BUD (3mg, three times daily or twice daily) or } \\
\text { prednisone ( } 40 \mathrm{mg} / \mathrm{d} \text {, tapered to } 10 \mathrm{mg} / \mathrm{d}) \text {. } \\
\text { Follow-up duration: } 6 \text { months } \\
\text { Primary endpoint: induction of remission } \\
\text { Definition of remission: normal serum levels of } \\
\text { aspartate aminotransferase and alanine } \\
\text { aminotransferase, without predefined steroid- } \\
\text { specific side effects, at } 6 \text { months. }\end{array}$ & $\begin{array}{l}\text { Study completer: } 207 \text { completers. } \\
\text { 102: BUD- AZA versus } 105 \text { Prednisone-AZA } \\
\text { Result: complete biochemical in } 60 \% \text { of BUD group } \\
\text { versus 38.8\% of prednisone group (P = .001; CI: 7.7) } \\
\text { Limitation: } \\
\text { Conclusion: Oral BUD, in combination with } \\
\text { azathioprine, induces and maintains remission in } \\
\text { patients with noncirrhotic AIH, with a low rate of } \\
\text { steroid-specific side effects. }\end{array}$ \\
\hline & & $\begin{array}{l}\text { Study design: Multicenter, retrospective study. } \\
\text { Study aim: To assess the efficacy and tolerability of } \\
\text { BUD as }\end{array}$ & $\begin{array}{c}\text { Study completer: } 18 \text { Participants (15 females, } 3 \\
\text { male) } \\
\text { Result: Complete response and remission were } \\
\text { achieved in } 61.1 \%(11 / 18) \text { of patients, while } 38.9 \% \\
\text { (7/18) of patients were considered treatment } \\
\text { failures. }\end{array}$ \\
\hline
\end{tabular}




\begin{tabular}{|c|c|c|c|}
\hline 4 & Efe et $\mathrm{al}^{7}$ & $\begin{array}{l}\text { an alternative first line treatment option for AIH. } \\
\text { Inclusion criteria: AIH patient who initially treated } \\
\text { with BUD. } \\
\text { Treatment regimen: Daily 9mg BUD plus 50mg AZA. } \\
\text { Follow-up duration: mean of } 9.2 \text { months } \\
\text { Primary endpoint: induction of remission. } \\
\text { Definition of remission: normalization of AST } \\
\text { and/or ALT while under budesonide treatment. }\end{array}$ & $\begin{array}{l}\text { Limitation: Small sample size. } \\
\text { Conclusion: BUD is an effective treatment option for } \\
\text { the management of AIH, with a low incidence of side } \\
\text { effects in patients without findings of advanced liver } \\
\text { disease. }\end{array}$ \\
\hline 5 & $\begin{array}{c}\text { Woynarowskiet } \\
\text { al }^{8}\end{array}$ & $\begin{array}{c}\text { Study design: prospective, double-blind, } \\
\text { randomized, active-controlled, multicenter phase } \\
\text { IIb study. } \\
\text { Study aim: To compare oral BUD with oral } \\
\text { prednisone in combination with AZA In AIH } \\
\text { patients. } \\
\text { Inclusion criteria: Patients with AIH aged 9-17 } \\
\text { years. } \\
\text { Treatment regimen: BUD } \\
\text { (3mg twice or } 3 \text { times daily) vs prednisone } \\
\text { (1-2mg/kg/day) } \\
\text { Follow-up duration: } 6 \text { months } \\
\text { Primary endpoint: Complete response to therapy. } \\
\text { Definition of remission: complete biochemical } \\
\text { remission. }\end{array}$ & $\begin{array}{l}\text { Study completer: } 46 \text { Participants (11 males and } 35 \\
\text { females) } \\
\text { Result: no statistically significant difference in the } \\
\text { percentage of patients who met the primary } \\
\text { endpoint between the budesonide ( } 3 \text { of } 19 ; 16 \% \text { ) and } \\
\text { prednisone groups ( } 4 \text { of } 27 ; 15 \% \text { ) after } 6 \text { months. } \\
\text { Limitation: relatively short study period. } \\
\text { Conclusion: Oral BUD with AZA can induce and } \\
\text { maintain remission in pediatric patients with AIH } \\
\text { and may be considered an alternative therapy to } \\
\text { prednisone. }\end{array}$ \\
\hline
\end{tabular}


Figure 1: Flow diagram through the different phases of the systematic review (PRISMA flowchart)
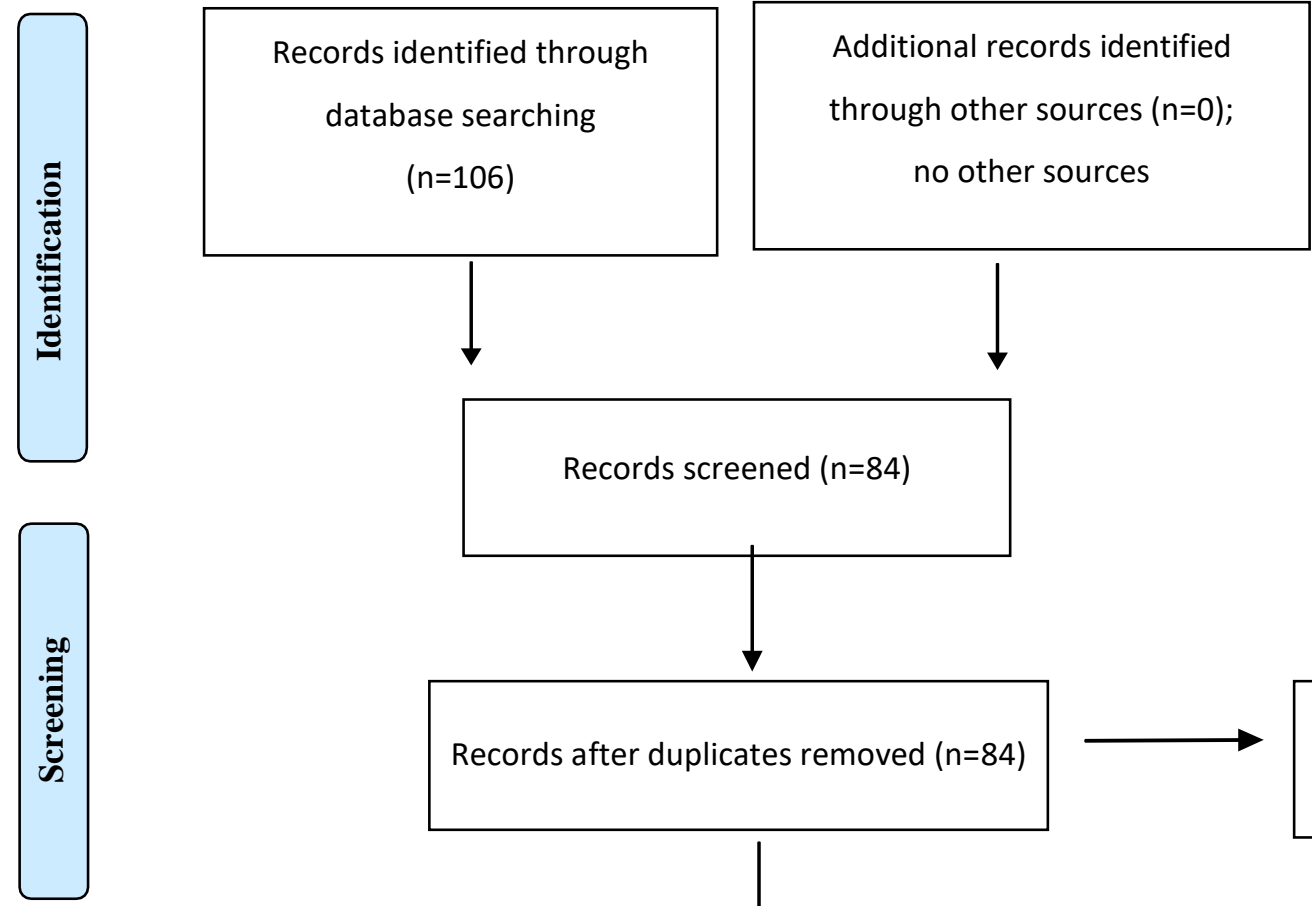

Records screened $(n=84)$
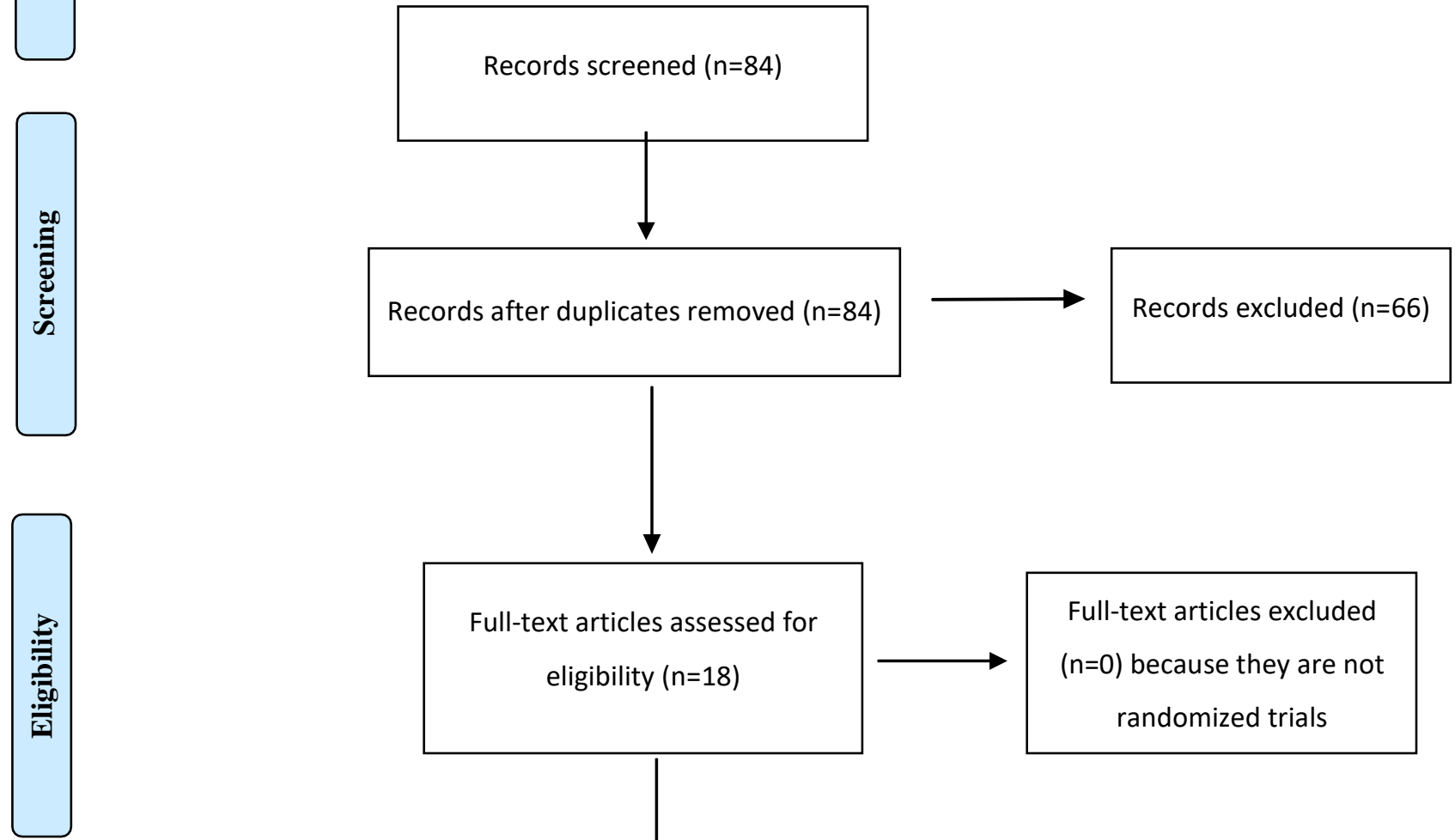

苞

Studies included in the qualitative synthesis $(n=5)$ 